\title{
Science communication research in the German-speaking countries: A content analysis of conference abstracts
}

Sabrina Heike Kessler*, University of Zurich, Department of Communication and Media Research Birte Fähnrich, Berlin-Brandenburg Academy of Sciences and Humanities (BBAW)

Mike S. Schäfer, University of Zurich, Department of Communication and Media Research

Corresponding author: s.kessler@ikmz.uzh.ch

\begin{abstract}
The study examines the state of science communication research in the German-speaking countries. Based on a standardized content analysis of all extended abstracts submitted to the annual conferences of the German Communication Association's science communication division from 2014 to $2018(N=141)$, it describes the respective scholarly community, its research foci and objects. The results indicate that science communication has developed toward a well-established community and marks an institutionalization of the research field. Furthermore, the findings of the content analysis indicate that science communication research in the German-speaking countries shows parallels to international developments in terms of research foci, objects, and analytical models, but also differences regarding theories and methods.
\end{abstract}

Keywords

science communication research, conference abstracts, scholarly community, German-speaking countries

\section{Introduction and research questions}

Science communication has gained importance in recent years (Bubela et al., 2009; Bucchi \& Trench, 2014; Schäfer, Kessler, \& Fähnrich, 2019) and is an expanding field of practice. Correspondingly, research on science communication has grown internationally, particularly in the Anglo-American countries (for overviews, see Bucchi \& Trench, 2014; Jamieson, Kahan, \& Scheufele, 2017). In Germany, Austria, and Switzerland, in contrast, such research was still in its infancy until just a few years ago. Apart from individual studies focusing on science journalism or the communication of specific science issues (e.g., Hampel \& Renn, 1999; Kohring, 1997), science communication research emerged a mere 15 years ago, driven by German Research Foundation funding schemes such as "Science and the Public" (2009-2015) and large funding programs by the German Federal Ministry of Education and Research for biotechnology or climate change communication. In recent years, however, the field has expanded in German-speaking countries, with several chairs for science communication established at universities in Dresden (GER), Göttingen (GER), Karlsruhe (GER), Passau (GER), and Zurich (CH). German-language anthologies and handbooks were published (Bonfadelli et al., 2017; Dernbach, Kleiner, \& Münder, 2012; Fähnrich, Metag, Post, \& Schäfer, 2018; Ruhrmann, Kessler, \& Guenther, 2016; Schäfer, Kristiansen, \& Bonfadelli, 2015b), and the German Communication Association's science communication division was founded in 2012. These developments indicate the institutionalization of the field in German-speaking countries.

But apart from these institutional and structural indicators, little is known about the development of the field in terms of its scholarly orientation - its topics, approaches, methods and representatives. This study provides answers to these questions, analyzing the field's characteristics and growth. 
, RQ1: How can the science communication research community of the science communication division in German-speaking countries be described?

, RQ2: Which objects and models as well as theoretical and methodological approaches are characteristic of the research?

These questions are answered on the basis of a content analysis of all abstracts that were submitted to five annual conferences of the German Communication Association's science communication division. Results are then compared to the international development of science communication research.

This article begins with a brief outline of international developments, presents the results of the content analysis, and concludes with a discussion and perspectives for further research.

\section{Science communication as a dy- namic international research field}

To analyze science communication as a distinct field of social science research requires a definition of the concept. Science communication been defined in various ways emphasizing different forms, objectives or means (Burns, O'Connor, \& Stocklmayer, 2003). Accordingly, these definitions focus on specific aspects of science communication. However, to analyze the field in its entirety, a broader and more comprehensive definition seems more adequate. Against this backdrop, we define science communication as "all forms of communication focusing on scientific knowledge or work, both within and outside institutionalized science, including its production, content, use, and effects" (Schäfer, Kristiansen, \& Bonfadelli, 2015a, p. 13) and thus covering, for example, knowledge transfer to nonscientists and public dialogue about science- (Bubela et al., 2009; Bucchi \& Trench, 2014; Schäfer, Kessler, \& Fähnrich, 2019). In a broad sense, "science communication encom-

1 This quote was translated into English by the authors, as were several others. passes all forms of communication by and about the sciences, within science (professional audience) as well as in the science-external public sphere (general audience)" (Acatech, 2017, p. 20; cf. Bubela et al., 2009; Bucchi \& Trench, 2014; Schäfer et al., 2015a).

Internationally, science communication has become a dynamic field of research that has received political support around the globe (for an overview, see Bauer, 2017; Bucchi \& Trench, 2014; Jamieson et al., 2017). Its growth and development manifests itself in various ways: the establishment of professional associations, such as the Network for the Public Communication of Science and Technology (PCST); the emergence and increasing impact of journals, such as Public Understanding of Science, Science Communication, and JCOM-Journal of Science Communication; the considerable number of introductory handbooks (e.g., Bauer \& Bucchi, 2007; Bucchi \& Trench, 2014; Fischhoff \& Scheufele, 2013; Jamieson et al., 2017); the increase in university chairs and courses devoted to it (Gascoigne et al., 2010); and the existence of a growing and increasingly diverse scholarly community, as visible in bibliometric analysis (Rauchfleisch \& Schäfer, 2018).

Internationally, a number of meta-analyses and literature reviews (e.g., Bucchi \& Trench, 2014; Guenther \& Joubert, 2017; Kahan et al., 2017; Schäfer, 2012; Trench et al., 2014) have described characteristics and trends of science communication research, albeit mostly focusing on English-speaking countries. They have shown that the research community is rooted in different disciplines and, consequently, includes theories and methods from a range of disciplines such as psychology, pedagogy, sociology, economics, linguistics, and communication science (Fischhoff \& Scheufele, 2013; Kahan et al., 2017; Trench et al., 2014).

Furthermore, they have demonstrated that the objects of science communication research come primarily from the natural sciences and the STEM subjects (Schäfer, 2012). Research has only recently begun to include the social sciences, the arts, and 
humanities (Guenther \& Joubert, 2017; Schäfer, 2012). They have also demonstrated that the geographic scope of most research does not extend beyond individual and predominantly Western countries, mainly considering national frameworks and influencing factors (Schiele, Claessens, \& Shi, 2012). Comparative studies across countries are an exception.

Science communication research applies diverse qualitative and quantitative methodological approaches (Schäfer 2012; Schäfer et al., 2019). Surveys, content analyses, and literature reviews appear most frequently (Schäfer, 2012).

Different models of science communication also have their origins in science policy (Akin \& Scheufele, 2017). The first such perspective, established in the 1960s, is the deficit model (Bauer \& Falade, 2014; Bucchi \& Trench, 2014), which sees science communication mainly as an instrument to inform the lay public about science, using unidirectional communication as an appropriate means for transferring knowledge. During the 1980s and 1990s, a second perspective emerged, focusing on public understanding of science: scientific knowledge should no longer merely be transferred but should contribute to improving science literacy in society. A third perspective took hold in the 1990s and 2000s, with the emergence of public engagement with science initiatives aiming for dialogue between science and society (Bubela et al., 2009). Akin and Scheufele (2017) argued that a fourth perspective has appeared, emphasizing the often conflictual and controversial debates about science in political and sociopolitical contexts. Descriptions of industrialized countries with longer traditions of science communication show shifts away from the deficit model toward dialogue-oriented approaches (Schäfer et al., 2015a; Schiele et al., 2012; Trench et al., 2014).

\section{Data and method}

Despite these general international trends, science communication research has been shown to vary from country to country, due to different national policies, research agendas, and sociocultural conditions (Schiele et al., 2012; Trench et al., 2014). In light of these differences and because no analysis has specifically focused on this region, we analyzed the development of science communication research in the German-speaking countries.

The state and development of such a field can be evaluated in various ways, e. g., by using bibliometric analyses of scholarly publications (e.g., Rauchfleisch \& Schäfer, 2018), providing meta-analyses of journal articles (e.g., Guenther \& Joubert, 2017; Schäfer, 2012), or surveying scientists (e.g., Peters, 2013). We analyze submissions to scientific conferences, conducting a quantitative content analysis of all extended abstracts that were submitted to all annual conferences of the German Communication Association's science communication division that were held to date. This approach seemed appropriate for several reasons. First, conferences have been shown to play a central role in establishing new research fields (Clark, 1972), and science communication is still such a young field in the German-speaking countries. Second, the analysis of submissions to a specific type of conference allows us to focus on the precise geographic region that interests us. While we analyze the German association for communications' division of science communication, it serves as the meeting and reference point for Austrian and Swiss colleagues as well. In Austria and Switzerland, the professional associations of communication researchers are considerably smaller and have no specific working groups on science communication. Therefore, researchers from these countries attend the German conferences, too, and thus are included in this study. Third, even though the analyzed conferences had different foci, all tried to encapsulate the entire science communication community by choosing rather general foci. Relevant to this, all the conferences were open to empirical as well as theoretical contributions.

A standardized content analysis was conducted to capture formal and content-related characteristics of all abstracts 
$(N=141)$ submitted to the five annual conferences between 2014 and 2018. Deductively, the codebook focused in particular on international content analyses in this area (Schäfer, 2012; Schäfer \& Schlichting, 2014) and contained community-related categories, such as how many authors submitted an abstract and their institutional affiliation, content-related categories, such as the analyzed scientific discipline and analyzed country, categories concerning the methods and research designs, the theories used, and variables related to the models of science communication (see Table 1). There were two coders, and intercoder reliability was satisfactory (see Table 1).

The lowest intercoder agreement was found for the coding of the models of science communication (such as the "public understanding of science" or "public engagement") in the abstracts. Seventeen percent of the abstracts could not be as- signed here. The variable was coded (a) if the submissions were based on the deficit model assumption, meaning the purpose of science communication is to transfer knowledge from science to enlighten the public. It was coded (b) if the public understanding of science assumption was central to the submissions; that is, the dialogue between science and the lay public aims to make scientific content and processes accessible and comprehensible to the public. Unlike the deficit model, this is not about the effect on and deficit of knowledge but rather the effects of communication on (deficit) attitudes. It was coded (c) if the engagement of science assumption was central and the active participation of laypeople in science communication was taken into account. This is about public engagement that is intended to encourage people to participate in science and to achieve a stronger involvement of the public in the scientific

Table 1: Variables and intercoder reliability

\begin{tabular}{|c|c|c|c|c|}
\hline Variable & Variable type & Possible codes & $\begin{array}{l}\text { Holsti (with order) } \\
\qquad n=15\end{array}$ & $\begin{array}{l}\text { Krippendorff's Alpha } \\
\qquad n=15\end{array}$ \\
\hline Year of the conference & formal & 5 & 1 & 1 \\
\hline \multicolumn{5}{|l|}{ Authors } \\
\hline quantity & formal & open & 1 & 1 \\
\hline gender & formal & 2 & 1 & 1 \\
\hline academic degree & formal & open & 1 & 1 \\
\hline institutions & formal & open & 1 & 1 \\
\hline country & formal & open & 1 & 1 \\
\hline institution type & formal & 7 & 1 & 1 \\
\hline \multicolumn{5}{|l|}{ Submissions } \\
\hline $\begin{array}{l}\text { analyzed science } \\
\text { discipline }\end{array}$ & content-related & open & 0.86 & 0.81 \\
\hline type of examination unit & content-related & open & 0.92 & 0.81 \\
\hline analyzed country & content-related & open & 1 & 1 \\
\hline data originality & content-related & 2 & 1 & 1 \\
\hline method type & content-related & 4 & 1 & 1 \\
\hline explicit method & content-related & 8 & 0.80 & 0.77 \\
\hline research design & content-related & 7 & 0.90 & 0.89 \\
\hline research focus & content-related & 7 & 0.90 & 0.88 \\
\hline $\begin{array}{l}\text { disciplines of models / } \\
\text { theories }\end{array}$ & content-related & 7 & 0.90 & 0.86 \\
\hline explicit theories & content-related & open & 0.90 & 0.87 \\
\hline $\begin{array}{l}\text { science communication } \\
\text { models }\end{array}$ & evaluated & 7 & 0.70 & 0.60 \\
\hline
\end{tabular}


community. It was coded (d) if the context (e.g., social or political) of science communication was central to and the focus of the abstracts.

\section{Results}

The five conferences received 141 submissions (2014 Zurich (CH) $n=38 ; 2015$ Jena (GER) $n=31 ; 2016$ Dresden (GER) $n=26 ; 2017$ Landau (GER) $n=25 ; 2018$ Friedrichshafen (GER) $n=21$ ). Those were submitted by a total of 325 authors; $31 \%$ of which submitted an abstract to several annual conferences $(n=107)$. Most submissions had one $(n=47 ; 33 \%)$, two $(n=42$; $30 \%)$, or three $(n=31 ; 22 \%)$ authors.

RQ1 can be answered by examining these authors and their characteristics. Women were a slight majority $(n=188$; $58 \%) ; 26 \%$ of authors were professors $(n=81), 35 \%$ postdocs $(n=112), 31 \%$ doctoral students $(n=97)$, and $9 \%$ students $(n=27) .^{2}$ The authors came from 64 different institutions: universities $(n=286$, $72 \%)$, public research institutes $(n=17$, $4 \%)$, private research institutes $(n=12,3 \%)$, and universities of applied sciences $(n=4$, $1 \%)$. Furthermore, they were mostly from Germany ( $n=252,63 \%)$, with Switzerland accounting for $10 \%(n=39)$ and Austria for $4 \%(n=14)$. The authors were mostly communication scientists $(n=218,84 \%)$. Sociologists made up 3\% $(n=9)$ and other social science scientists up to $11 \%(n=17$; e. g., psychologists $n=5,2 \%$ ).

RQ2 was concerned with the characteristics of the research presented in the analyzed conference submissions. The analysis shows that the respective studies dealt with a large spectrum of objects. First, they focused on the communication about different scientific disciplines: $38 \%$ of the submissions analyzed communication about science in general $(n=54)$; however, about one third focused on communication about STEM disciplines, such as climate science $(n=27,19 \%)$, medicine $(n=18,13 \%)$, or nanotechnology $(n=6$,

2 However, women made up only $36 \%$ of professors, compared to $62 \%$ of postdocs and $72 \%$ of doctoral candidates.
$4 \%)$. Second, they addressed different kinds of communication: most focused on communication from mass media $(n=61$, $43 \%)$ and institutions ( $n=39,28 \%)$ rather than interpersonal communication ( $n=15$, $11 \%)$. Third, most submissions concerned research on the communicators $(n=41$, $29 \%$ ), effects of science communication on individuals $(n=28,20 \%)$ and society ( $n=12,9 \%$ ), contents of science communication ( $n=22,16 \%)$, science journalism ( $n=19,14 \%)$, and reception of science communication ( $n=15,11 \%)$. Fourth, the applied theories mostly came from communication science $(n=21,15 \%$; e.g., framing or agenda setting theory), sociology ( $n=10,7 \%)$, psychology ( $n=8,6 \%$; e.g., theory of planned behavior or dual process theory of attitude formation), political science $(n=6,4 \%)$, and economics $(n=2,1 \%)$.

The spectrum of methods proved to be rather narrow: the submissions mostly used surveys ( $n=60,43 \%)$ and content analyses $(n=54,38 \%)$ rather than observational methods $(n=8,6 \%)$. Moreover, comparative studies were found to be the most important research design $(n=50$, $36 \%$ ). A smaller number of studies had an experimental design ( $n=11,8 \%)$. Eighteen submissions $(13 \%)$ were solely theoretical. A majority of the empirical papers used original data $(n=108,77 \%)$, and only a few relied on secondary data $(n=15,11 \%)$. Research objects were mostly print media (such as daily newspapers and magazines, $n=85,60 \%)$, survey data $(n=60,43 \%)$, websites (such as online formats of journalistic media, blogs, user comments, and social media sites, $n=34,24 \%$ ), television programs $(n=12,9 \%)$, and scholarly papers $(n=10,7 \%)$. In almost half the cases ( $n=65,46 \%$ ), the analyses were quantitative, with qualitative analyses accounting for $19 \%(n=27)$ and combinations of both for $16 \%(n=22)$.

Almost a third of the analyses explicitly or implicitly applied the assumptions of the public understanding of science model $(n=42,30 \%)$. This included submissions that analyzed the scientific literacy of the population in a representative survey or by using an online experiment - whether scientific results were understood. Sub- 
missions concerning the deficit model $(n=11,8 \%)$ and public engagement of science $(n=12,9 \%)$ were considerably scarcer. Submissions concerning the deficit model addressed, for example, the best way to convey scientific knowledge to the public. Submissions concerning the $p u b$ lic engagement of science included whether scientific events, such as science pubs or the March of Science, promote the involvement of lay people in science. However, most research focused on the context of science communication ( $n=53,38 \%$ ). This includes studies in which the social or political context of science communication is in the foreground, such as studies that interview climatologists on the public role and policy relevance of the climate change, and studies that examine the legitimization of national and global climate change policies in the domestic media.

\section{Discussion}

The analysis of all submissions to the annual conferences of the German Communication Association's science communication division shows a lively and diverse community of researchers that is well balanced in terms of gender and academic status groups - similar to that in other countries (Bucchi \& Trench, 2014; Guenther \& Joubert, 2017; Kahan et al., 2017; Schäfer, 2012; Trench et al., 2014). Researchers from a large number of institutions applied to the conferences, even though scholars from universities predominated. While the high share of communication scientists is natural for a conference in this discipline, the conferences were able to attract scholars beyond communication science, indicating that science communication might develop into a more interdisciplinary community that could benefit from mutual exchange (Fischhoff \& Scheufele, 2013; Kahan et al., 2017; Trench et al., 2014). Moreover, submissions from Austrian and Swiss authors indicate that science communication is also established beyond Germany, particularly at universities in Switzerland. That almost a third of all abstracts come from authors who also submitted to other annual conferences indicates a certain establishment of the community.

The conference submissions dealt with a broad spectrum of research objects. However, even though different disciplines were analyzed, the large majority focused on STEM subjects (such as climate science, medicine, or nanotechnology), whereas research on humanities and social sciences was less prevalent (Schäfer, 2012; Schäfer et al., 2019). The results show a research focus on specific topics, especially climate change - internationally, the spectrum of objects is broader and medical science plays a more important role (Schäfer, 2012). An explanation for this can be found in the existence of a health communication section in the German Communication Association, which deals especially with topics of medical science communication. The strong focus on the analysis of communicators and communication content and the comparatively weak focus on impact studies could also be considered specific to the research of the German-speaking countries (Schäfer et al., 2019); nevertheless, systematic meta-analytic, international comparative research is still absent.

Similar to the global trend (Bucchi \& Trench, 2014; Kahan et al., 2017; Schäfer, 2012; Trench et al., 2014), a broad range of theories and empirical approaches from various disciplines appears, with communication science being only one root (see also Rauchfleisch \& Schäfer, 2018). Whereas the field thus shows parallels to international developments of the (interdisciplinary) science communication field, German science communication research clearly demonstrates that it developed as a subfield of communication science. For instance, the diversity of theories and methods applied in science communication research is also evident in the entire field of communication science in the German-speaking countries (Altmeppen, Weigel, \& Gebhard, 2011). Content analyses and surveys are common methods, and there is a clear majority of quantitative research designs (similar to communication 
science in the German-speaking countries in general; Altmeppen et al., 2011).

With regard to the international science communication developments, these results show interesting parallels between the German-speaking research community and other industrialized and emerging countries, such as Australia, the US, and China, but also differences regarding research methods, the general significance of the topic, and the prevailing models of science communication (Schiele et al., 2012; Trench et al., 2014). The research field's overall shift from the deficit model of science communication to a dialogue orientation is also apparent in the German-speaking field. The importance of the models varies between countries depending on domestic policies and sociocultural conditions (Schiele et al., 2012; Trench et al., 2014). In particular, descriptions of industrialized countries with longer traditions of institutionalized science communication (research), such as many European countries, show shifts away from the deficit model toward dialogue-oriented approaches (Schäfer et al., 2015a; Schiele et al., 2012; Trench et al., 2014). Few of the investigated conference studies are embedded in the deficit mod$e l$. However, there are also relatively few focusing on public engagement of science, which is regarded as more progressive and democratic because it takes into account the active participation of laypeople in science communication. Most of the studies were based on the public understanding of science model and the model of contextualized science communication (Akin \& Scheufele, 2017). The similarities to other developed countries indicate that the field in German-speaking countries, although relatively newer, is keeping pace with that of English-speaking countries.

We have to emphasize, however, that our analysis is limited in scope and merely a starting point for future research. While the analyzed data represent all applicants of the respective science communication conferences, they may not be representative for the population of science communication researchers in German-speaking countries as a whole. Conference submis- sions are only one indicator for the research activities in the field, in addition to, for example, publications and third-party funding. Longitudinal analyses would be helpful to assess the development of the field. Moreover, bibliometric analyses or meta-analyses would complement our analysis as well (e.g., Rauchfleisch \& Schäfer, 2018).

\section{References}

Acatech (2017). Social media and digital science communication. Position Paper. Munich: acatech - National Academy of Science and Engineering.

Altmeppen, K.-D., Weigel, J., \& Gebhard, F. (2011). Forschungslandschaft Kommunikations- und Medienwissenschaft [Research field communication and media science]. Publizistik, 56(4), 373-398. doi:10.1007/s11616-011-0132-7

Akin, H., \& Scheufele, D. A. (2017). Overview of the science of science communication. In K. H. Jamieson, D. M. Kahan, \& D. Scheufele (Eds.), The Oxford handbook on the science of science communication (pp. 25-33). Oxford: Oxford University.

Bauer, M. W. (2017). Kritische Beobachtungen zur Geschichte der Wissenschaftskommunikation [Critical observations on the history of science communication]. In H. Bonfadelli, B., Fähnrich, C. Lüthje, J. Milde, J., M. Rhomberg, \& M. S. Schäfer (Eds.), Forschungsfeld Wissenschaftskommunikation [Research field science communication] (pp. 17-40). Wiesbaden: Springer.

Bauer, M. W., \& Bucchi, M. (Eds.). (2007). Science, journalism and society: Science communication between news and public relations. London: Routledge.

Bauer, M. W., \& Falade, B. A. (2014). Public understanding of science: Survey research around the world. In M. Bucchi, \& B. Trench (Eds.), Handbook of public communication of science and technology (pp. 140-159). London: Routledge.

Bonfadelli, H., Fähnrich, B., Lüthje, C., Milde, J., Rhomberg, M., \& Schäfer, M. S. (Eds.). (2017). Forschungsfeld Wissenschaftskom- 
munikation [Research field science communication]. Wiesbaden: VS.

Bubela, T., et al., (2009). Science communication reconsidered. Nature Biotechnology, 27(6), 514-518. doi:10.1038/nbt0609-514

Bucchi, M., \& Trench, B. (2014). Science communication research: themes and challenges. In M. Bucchi, \& B. Trench (Eds.), Handbook of public communication of science and technology (pp. 1-14). London: Routledge.

Burns, T. W., O'Connor, D. J., \& Stocklmayer, S. M. (2003). Science communication: A contemporary definition. Public Understanding of Science, 12(2), 183-202. doi:10.1177/09636625030122004

Clark, T. N. (1972). The stages of scientific institutionalization. International Social Science Journal, 24, 658-671.

Dernbach, B., Kleiner, C., \& Münder, H. (Eds.) (2012). Handbuch Wissenschaftskommunikation [Handbook Science Communication]. Wiesbaden: Springer VS.

Fähnrich, B., Metag, J., Post, S., \& Schäfer, M. S. (Eds.) (2018). Forschungsfeld Hochschulkommunikation [The field of university communication]. Wiesbaden: Springer VS.

Fischhoff, B., \& Scheufele, D. A. (2013). The science of science communication. Proceedings of the National Academy of Sciences, 110, 14031-14032. doi:10.1073/pnas.1213273110

Gascoigne, T., Cheng, D., Claessens, M., Metcalfe, J., Schiele, B., \& Shi, S. (2010). Is science communication its own field? Journal of Science Communication, 9(3), 1-6. doi:10.22323/2.09030304

Guenther, L., \& Joubert, M. (2017). Science communication as a field of research: Identifying trends, challenges and gaps by analyzing research papers. Journal of Science Communication, 16(1), 1-19. doi:10.22323/2.16020202

Hampel, J., \& Renn, O. (1999). Gentechnologie in der Öffentlichkeit. Wahrnehmung und Bewertung einer umstrittenen Technologie [Genetic engineering in public. Perception and evaluation of a controversial technology]. Frankfurt am Main: Campus.

Jamieson, K. H., Kahan, D., \& Scheufele, D. (2017). The Oxford handbook on the science of science communication. Oxford: Oxford University Press.
Kahan, D. M., Scheufele, D. A., \& Jamieson, K. H. (2017). Introduction: Why science communication? In K. H. Jamieson, D. M. Kahan, \& D. A. Scheufele (Eds.), The Oxford handbook on the science of science communication (pp. 1-11). Oxford: Oxford University Press.

Kohring, M. (1997). Die Funktion des Wissenschaftsjournalismus. Ein systemtheoretischer Entwurf [The function of science journalism. A system-theoretical design]. Opladen: Westdeutscher Verlag.

Peters, H. P. (2013). Gap between science and media revisited: Scientists as public communicators. Proceedings of the National Academy of Sciences, 110, 14102-14109. doi:10.1073/pnas.1212745110

Rauchfleisch, A., \& Schäfer, M. S. (2018). Structure and development of science communication research: Co-citation analysis of a developing field. JCOM - Journal of Science Communication, 17(3), 1-21. doi:10.22323/2.17030207

Ruhrmann, G., Kessler, S. H., \& Guenther, L. (Eds.). (2016). Wissenschaftskommunikation zwischen Risiko und (Un)Sicherheit [Science communication between risk and (un)certainty]. Köln: Herbert von Halem.

Schäfer, M. S. (2012). Taking stock: a meta-analysis of studies on the media's coverage in science. Public Understanding of Science, 21(6), 650-663. doi:10.1177/0963662510387559

Schäfer, M. S., Kessler, S. H., \& Fähnrich, B. (in press, 2019). Analyzing science communication through the lens of communication science: Reviewing the empirical evidence. In A. Lessmöllmann, M. Dascal, \& T. Gloning (Eds.), Science Communication (pp. 77-104). Berlin: de Gruyter Mouton.

Schäfer, M. S., Kristiansen, S., \& Bonfadelli, H. (2015a). Wissenschaftskommunikation im Wandel: Relevanz, Entwicklung und Herausforderungen des Forschungsfeldes [Changes in science communication: relevance, developments and challenges in the field of research]. In M. S. Schäfer, S. Kristiansen, \& H. Bonfadelli (Eds.), Wissenschaftskommunikation im Wandel [Changes in science communication] (pp. 10-42). Köln: Herbert von Halem. 
Schäfer, M. S., Kristiansen, S., \& Bonfadelli, H. (Eds.). (2015b). Wissenschaftskommunikation imWandel [Changes in science communication]. Köln: Herbert von Halem.

Schäfer, M. S., \& Schlichting, I. (2014). Media representations of climate change: A meta-analysis of the research field. Environmental Communication, 8(2), 142-160, doi:10.1080/17524032.2014.914050

Schiele, B., Claessens, M., \& Shi, S. (2012). Science communication in the world: practices, theories and trends. Dordrecht: Springer.
Trench, B., Bucchi, M., Amin, L., Cakmakci, G., Falade, B., Olesk, A., \& Polino, C. (2014). The global spread of science communication. In M. Bucchi, \& B. Trench (Eds.), Routledge handbook of public communication of science and technology (pp. 214230). London: Routledge. 
